\title{
МЕДИЦИНСКИ СПЕЦИАЛИСТИ ПО ЗДРАВНИ ГРИЖИ В СИСТЕМАТА НА ЗДРАВЕОПАЗВАНЕТО ЗА ПЕРИОДА 2005-2016 Г.
} К. Дикова, Б. Робев

\section{AUXILIARY MEDICAL PERSONNEL IN THE HEALTHCARE SYSTEM FOR THE PERIOD 2005-2016}

\author{
K. Dikova, B. Robev
}

Резюме. В макрорамката на иялата здравна система, човешкият потенциал заема водещь място. Съществува определена зависимост между структурните и качествените характеристики на здравния персонал от една страна, и развитието на здравната система от друга. Настоящото изследване обхваща всички болнични заведения (болници и центрове със стачионар), лечебните заведения за извънболнична помощ -медицинските иентрове, денталните иентрове, медико-денталните центрове, диагностично-консултативните центрове, самостоятелните медико-диагностични и медико-технически лаборатории. Данните за медииинските специалисти по здравни грижи по видове показват техния брой и относителен дял в общия брой, където е най-голям делът на медицинските сестри. Показателите за осигуреността с медииински сестри за по-голям период, показват добре изразена динамика. Важен показател за състоянието и развитието на медицинския персонал е съотношението лекари сестри.Този показател е от значение, както за обема, така и за качеството на извъриваната медицинска дейност в лечебните заведения.

$\boldsymbol{S}$ u $\mathbf{m} \boldsymbol{m}$ a ry. In the macro frame of the entire health system, human potential takes the lead. There is a definite correlation between the structural and qualitative characteristics of healthcare personnel on the one hand and the development of the healthcare system on the other.The survey covers all health establishments for hospital care (hospitals and stationary centers), outpatient health care establishments - medical centers, dental centers, medical-dental centers, diagnostic and counseling centers, independent medical-diagnostic and medical-technical laboratories. Data on auxiliary medical personnel by type show their number and rate in the total number, where the proportion of nurses is the highest. Indicators of long-term nursing provision show well-expressed dynamics. An important indicator of the state and development of medical personnel is the ratio of nursing and doctors. This indicator is important both for the volume and the quality of the medical activity in the medical establishments.

И зползвани са данни за дванадесет годишен период - от 2005 до 2016 година от официалните източници на здравна информация в страната - Националния статистически институт и дирекция Национални здравни данни и електронно здравеопазване към Националния център по обществено здраве и анализи. Представена е информация за медицинския персонал - медицински специалисти по здравни грижи по категории персонал, видове заведения, възраст, общо за страната и по области. Приложена е Класификацията на териториалните единици за статистически цели в България (NUTS).

В броя на медицинския персонал (физически лица) се включват практикуващите в лечебните и здравните заведения, независимо от ведомствената подчиненост на заведенията. Включват се и медицинските специалисти, работещи в самостоятелни детски ясли и яслени групи в състава на детски градини, индивидуалните и групови практики за пьрвична и специализирана медицинска и дентална помощ, медицинския персонал към общините (заети в училищно здравеопазване и детски ясли).

Не са включени данни за работещите извън страната медицински специалисти и за тези, които не работят непосредствено в здравните заведения - напр. във фармацевтичната промишленост.

Осигуреността на населението с медицински персонал е изчислена с броя на населението към края на съответната година. Статистическа единица са практикуващите медицински специалисти (физически лица), работещи на основен трудов договор.

Данните за медицинските специалисти в индивидуалните и групови практики за първична и специализирана медицинска и дентална помощ се получават от Националната здравноосигурителна каса, за лицата, сключили договор с нея.

В съвкупността на другите лечебни и здравни заведения са включени: центровете за спешна медицинска помощ, самостоятелните центрове за трансфузионна хематология, хосписите, медицинските университети и колежи, общините - за медицинския персонал в училищата на издръжка от общината, националните центрове без легла, регионалните здравни инспекции, домовете за медико-социални грижи за деца.

Данните са от административни източници.

Обхваща се цялата територия на Република България. В териториален разрез данните се представят според административно-териториалното деление на страната към 31.12. на съответната година.

Анализът е структуриран в следните раздели:

- Медицински специалисти по здравни грижи на 31.12

- Медицински специалисти по здравни грижи на 31.12. по категории;

- Медицински специалисти по здравни грижи на 31.12. по области;

- Медицински специалисти по здравни грижи на 31.12. 2016 г. по възраст и по области.

\section{Медицински специалисти по зАравни грижи на 31.12}

На 31.12.2016 г. броят на медицинските специалисти по здравни грижи е 46930, като той е с 1.5\% по-малък в сравнение с 2005 г. и по-малък в сравнение с всички години на разглеждания период.

Осигуреността с медицинските специалисти по здравни грижи е 66.1 на 10 хиляди население за 2016 г. при $61.7 \%$ за 2005 г. (Фигура 1)

\section{Медицински специалисти по зАравни грижи на 31.12. по категории}

Разгледани са следните категории: медицински специалисти по здравни грижи: медицински сестри, акушерки, фелдшери, медицински лаборанти, рехабилитатори, рентгенови лаборанти, зъботехници. 
Фигура 1. Медищински специиалисти по здравни грижи (физически лииа) на основен трудов договор в лечебните и здравните заведения към 31.12.

\section{на 10000 население}

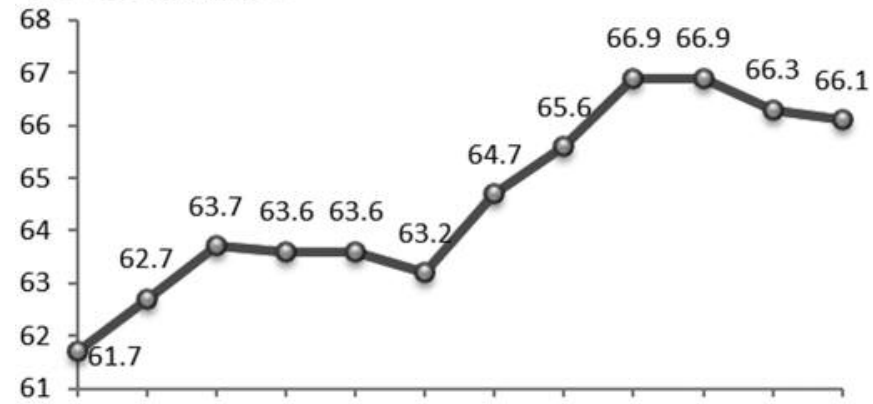

200520062007200820092010201120122013201420152016 Години

През периода 2010-2016 г. броят на медицинските специалисти по здравни грижи, както и осигуреността на 10 хиляди души население, разглеждан по категории, варира в тесни граници, както следва:

- осигуреността с акушерки от 4.3\%оо през 2010 г. нараства на 4.5\%оо през 2011 г., задържа се на това ниво до 2014 г. и нараства до 4.6\%оо през 2015 и 2016 г.;

- осигуреността с фелдшери от 3.2\%оо през 2010 г. след известно колебание достига 3.2\%оо през 2016 г;;

- осигуреността с медицински сестри (всички профили) от 42.4\%оо през 2010 г. също след известни колебания достига 43.6\%оо през 2016 г.;

- осигуреността с медицински лаборанти от 5.6\%оо през 2010 г. също след известно колебание нараства до 6.0\%оо през 2016 г;

- броят и осигуреността с рехабилитатори нарастват през периода 2010-2016 г., като осигуреността от 2.0\%оо през 2010 г. нараства до 2.3\%оо през 2016 г.;

осигуреността с рентгенови лаборанти от $2.0 \%$ през 2010 г. нараства на 2.4\%оо през 2016 г.;

- броят и осигуреността със зъботехници се колебаят през периода, като осигуреността с тях на 10 хиляди население от $1.7 \%$ о нараства на 2.2\%оо през 2016 г.

Данните за медицинските сестри в една по-дълга динамика - от 1990 до 2016 г. показват силно намаление на техния брой и интензивен показател. Осигуреността с медицински сестри от $62.1 \%$ оо през 1990 г. достига 43.6\%о през 2016 г., като бележи най-значително намаление от 55.2\%оо през 1999 г. на 38.6\%оо през 2000 г.

Фигура 2. Медиичнски сестри (всички профили) за периода 1990-2016 2.

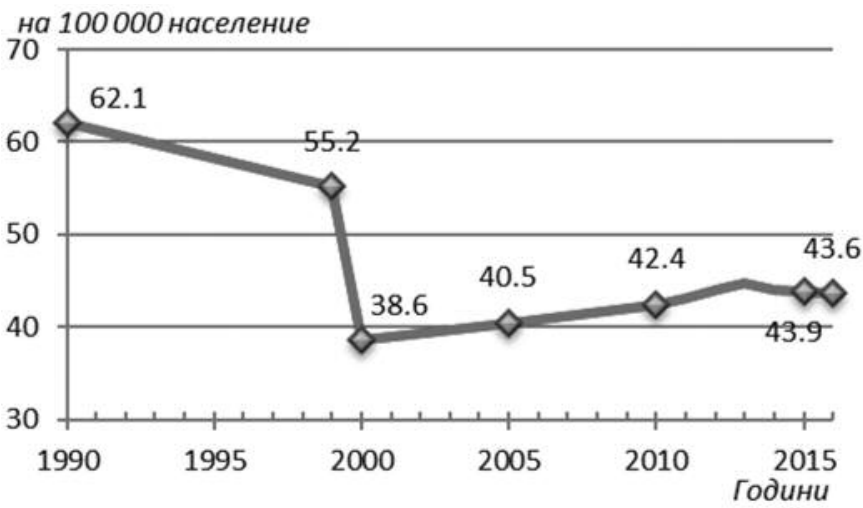

По данни на Евростат за 2015 г. осигуреността с медицински сестри в България - 437 на 100000 население е по-висока от тази в Гърция (321\%ооо) и по-ниска от същата в Полша (520\%ооо), Румъния (641\%ооо) и значително по-ниска от осигуреността с медицински сестри в Норвегия (1734\%оо) и Швейцария (1795\%ооо).

Фигура 3. Медицински сестри в някои европейски страни през 2015 2. (по данни на Евростат)

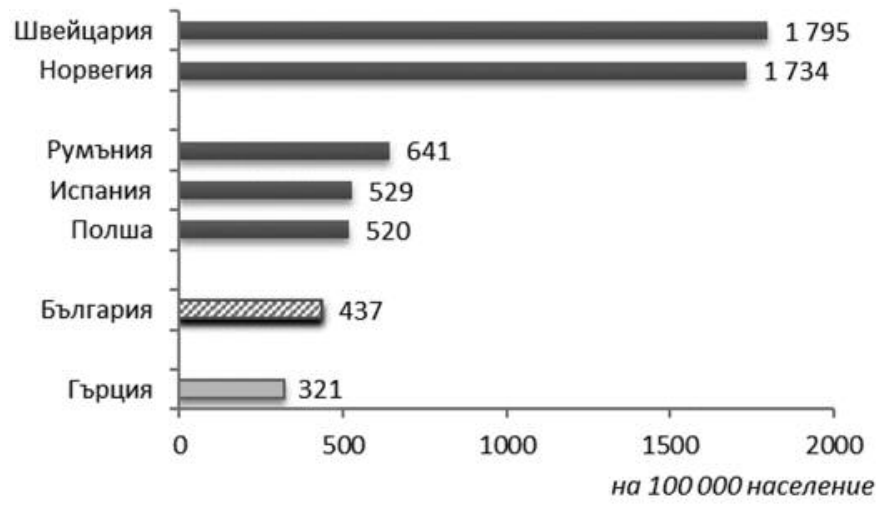

Към 31.12.2016 г. броят на медицинските специалисти по здравни грижи в лечебните и здравни заведения в страната е 46 930, в т.ч.:

- 2255 фелдшери $(4.8 \%)$

- 3254 акушерки (6.9\%),

- 30976 медицински сестри (66.0\%), $(12.7 \%)$,

5962 лаборанти (медицински и рентгенови)

- 1592 зъботехници (3.4\%).

Осигуреността на 10 хиляди от населението към 31.12.2016 г. с акушерки е 4.6, с фелдшери - 3.2, с медицински сестри (вкл. детски) - 43.6, с лаборанти (медицински и рентгенови) -8.4 , със зъботехници - 2.2.

\section{Медицински специалисти по зАравни грижи на 31.12.2016 г. по области}

Разгледан по области, общият брой на медицинските специалисти по здравни грижи и относителният дял $(\%)$, който съставляват от общия брой на медицинските специалисти по здравни грижи е с най-високи стойности за областите: София (столица) - 10047 и $21.4 \%$, Пловдив - 4757 и $10.1 \%$, Варна - 3020 и $6.4 \%$, Бургас - 2365 и 5.0\%. С наймалък брой и относителен дял (\%) са областите Видин - 466 и $1.0 \%$, Перник - 530 и $1.1 \%$, Разград - 561 и $1.2 \%$.

Осигуреността с медицинските специалисти по здравни грижи за 2016 г. варира от 42.8 на 10 хиляди население за област Перник до 84.2\%оо за област Плевен. Със стойности на показателя над този за страната е и осигуреността с медицинските специалисти по здравни грижи за област София (столица) (75.9\%оo), Габрово (73.5\%оо), Пловдив (70.8\%оo), Стара Загора (70.5\%оo), Враца (69.9\%оo).

Разглеждан по области към 31.12.2016 г. и при ранжиране в низходящ ред с най-голям брой и относителен дял $(\%)$ от общия брой фелдшери за страната са област Бургас - 152 и $6.7 \%$, област Русе - 119 и $5.3 \%$, а с най-малък брой и относителен дял е област София -23 и $1.0 \%$. С най-голям брой и относителен дял (\%) от общия брой акушерки са област София ( столица ) - 838 и $25.8 \%$, област Варна -296 и $9.1 \%$, а с най-нисък - област Ямбол - 31 и $1.0 \%$. и област Разград - 34 и $1.0 \%$. С най-голям брой и относителен дял (\%) от общия брой медицински сестри (вкл. детски) са област София (столица) - 6426 и 20.7\%, област Пловдив - 3137 и $10.1 \%$, а с най-нисък - област Видин - 269 и $0.9 \%$. Лаборантите (медицински и рентгенови), разглеждани по области, са с най-голям брой и относителен дял в област София (столица) -1468 и $24.6 \%$ и в област Пловдив -722 и $12.1 \%$, а с 
най-нисък - за област Видин - 45 и $0.8 \%$. Зъботехниците, разглеждани по области, са с най-голям брой и относителен дял в област София (столица) - 489 и $30.7 \%$, а с най-ниськ - в област Разград - 14 и $0.9 \%$.

Осигуреността на 10 хиляди население с фелдшери варира от 0.8 за област София (столица) до 8.7 за област Видин, с акушерки - от 1.7 за област Велико Търново до 6.6 за област Плевен, за медицински сестри (вкл. детски) - от 29.7 за област Разград до 56.1 за област Плевен, за лаборанти (медицински и рентгенови) - от 4.3 за област Перник до 12.7 за област Плевен, при зъботехници - от 0.8 за област Благоевград до 3.7 за област София (столица).

\section{Медицински специалисти по зАравни грижи на 31.12.2016 г. по възраст и по обцасти}

Анализът на възрастовата структура на медицинските специалисти по здравни грижи към 31.12.2016 г. общо за страната показва, че най-голям е относителният дял (\%) на медицинските специалисти по здравни грижи във възрастова група 55-64 г. - 29.3\%, следван от относителния дял на медицинските специалисти по здравни грижи на възраст 4554 години - 27.7\%. Медицинските специалисти по здравни грижи на възраст под 35 години имат относителен дял $13.2 \%$ от всички медицински специалисти по здравни грижи, тези на възраст 35-44 г. - 22.2\%, а на възраст над 65 години $7.6 \%$.

Фигура 4. Разпределение на медицинските специалисти по здравни грижи по възрастови групи през 2016 г.

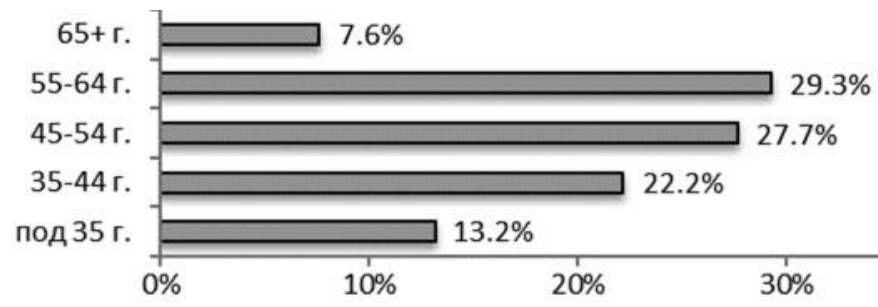

Данните по области показват, че в 16 от областите най-висок е относителният дял на медицинските специалисти по здравни грижи във възрастова група 55-64 г., а в 11 области най-висок е относителният дял на медицинските специалисти по здравни грижи на възраст 45-54 години. Над средния за страната относителен дял на медицинските специалисти по здравни грижи във възрастовата група 55-64 години (29.3\%) имат 16 области. С най-висок относителен дял на медицинските специалисти по здравни грижи в тази възрастова група са областите Перник (53.7\%), Кюстендил (53.1\%), Ямбол $(45.7 \%)$, а с най-ниски стойности на този показател са област Разград (18.9\%), област Варна (22.8\%).

С най-висок относителен дял на медицинските специалисти по здравни грижи на възраст 45-54 г. и по-висок от средния за страната (27.7\%) са областите Разград (36.5\%), Видин (34.1\%), Благоевград (32.7\%), а с най-нисък относителен дял (\%) е област Кюстендил (16.4\%).

В най-младите възрасти - под 35 години относителният дял (\%) на медицинските специалисти по здравни грижи по области е в границите от $2.7 \%$ (област Перник), $3.7 \%$ (област Габрово), 3.8\% (област Видин) до 22.2\% (област Плевен).

Във възрастовата група 35-44 г. относителният дял (\%) на медицинските специалисти по здравни грижи, разглеждан по области, варира от $13.5 \%$ (област Кюстендил), до $32.5 \%$ (област Кьрджали) и 28.2\% (област Бургас), във възрастовата група 65+ г. - от 3.8\% (област Стара Загора), до $15.7 \%$ (област Пазарджик)

Съотношението по специалности показва тревожна тенденция за изоставане на броя на медицинските сестри и акушерки в сравнение с лекарите медици. Тази диспропорция съществува в началото на наблюдавания период и се наблюдава в последствие през всяка една година до 2017 г.

Фигура 5. Дипломирани студенти по спещиалности за петгодишен период

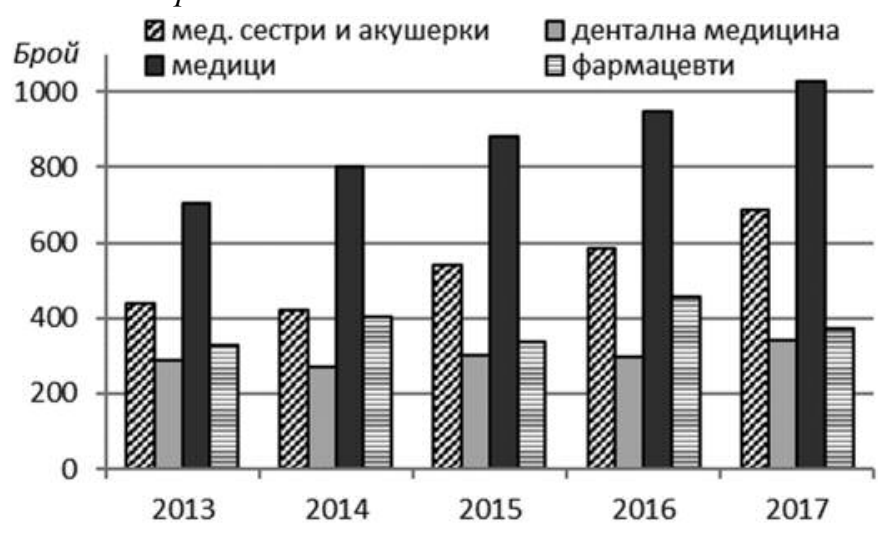

\section{Заключение}

1. Макар и с известни колебания през отделните години на периода 2005-2016 г., осигуреността с медицински специалисти по здравни грижи нараства и от $61.7 \%$ по през първата година на разглеждания период и достига $66.1 \%$ пре пре последната година.

2. Данните за медицинските специалисти по здравни грижи по видове показват, че най-голям е делът на медицинските сестри като през 2016 г. те съставляват $66 \%$ от всички медицински специалисти по здравни грижи. Данните за осигуреността с медицински сестри за по-голям период, показват добре изразена динамика. През 1990 г. този показател е $62.1 \%$ о, достига през 1999 г. 52.2\%оо, рязко намалява през 2000 г. до $38.6 \%$ оо след което постепенно нараства и достига 43.6\%оо през 2016 г.

3. Разпределението на медицинския персонал по здравни грижи в териториален аспект също е от съществено значение за осигуряване на адекватна медицинска помощ на населението в страната. Най-висока е осигуреността с медицински специалисти по здравни грижи в областите Плевен, София (столица) и Габрово, а най-ниска - в областите Перник, Добрич, Разград.

4. Възрастовото разпределение на медицинските специалисти по здравни грижи през 2016 г. показва, че найголяма част от тях $-29.3 \%$ са на възраст от 55 до 64 години, следвани от тези на възраст 45-54 години $-27.7 \%$. Медицинските специалисти по здравни грижи на възраст под 35 г. са $13.2 \%$, а тези над 65 г. възлизат на $7.6 \%$.

5. Важен показател за състоянието и развитието на медицинския персонал е съотношението лекари сестри, като хипотетично оптималното съотношение е определено за 1 лекар да бъдат осигурени 3 сестри. Този показател е от значение както за обема, така и за качеството на извършваната медицинска дейност в лечебните заведения.

През 2016 г. данните показват, че за България на 1 лекар се съотнасят 1.1 медицински сестри. За сравнение, в някои европейски страни това съотношение е 1 лекар към 2.3 сестри (Румъния и Полша), а в Норвегия същото съотношение е 1 лекар към 3.9 сестри.

6. Диспропорцията между лекарите и медицинските сестри е заложена още при тяхното обучение.

\begin{tabular}{l} 
Автори \\
Доц. Красимира Дикова, НЦОЗА \\
Д-р Божил Робев, УМБАЛ „Св. Иван Рилски” \\
\hline \hline
\end{tabular}

